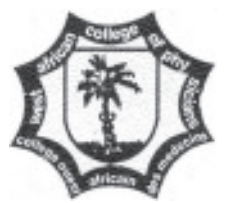

WEST AFRICAN JOURNAL OF MEDICINE

ORIGINAL ARTICLE

\title{
Trends in Regional Anaesthesia for Caesarean Section in a Nigerian Tertiary Health Centre
}

\author{
Tendances de l'anesthésie régionale en cas de césarienne dans un centre tertiaire de santé nigérian
}

\author{
M. A. Lamina
}

\begin{abstract}
BACKGROUND: Most caesarean sections were previously performed under general anaesthesia but there has been an increasing trend worldwide in the use of regional anaesthesia as the preferred method of anaesthesia for caesarean delivery. OBJECTIVE: To evaluate the trend of practice of regional anaesthesia for caesarean section in a tertiary hospital in South-western part of Nigeria.

METHODS: The obstetric operating room records at the Olabisi Onabanjo University Teaching Hospital, Sagamu, Nigeria were reviewed for a twenty-year period: January 1986 to December 2005. The anaesthetic techniques for caesarean section and the level of training of the attending anaesthetist were noted.

RESULTS: A total of 1,785 patients were delivered by caesarean section during the twenty-year period . Most patients [1578(88.4\%)] had caesarean section under general anaesthesia while $207(11.6 \%)$ had regional anaesthesia. Subarachnoid block accounted for 89(5\%) of the patients and $118(6.6 \%)$ had the caesarean section under epidural block. One hundred and ten $(21.5 \%)$ of the regional techniques were in the first quarter of the 20-year period. This figure fell to eight $(2 \%)$ in the second quarter; zero in the third quarter and rose to $82(13.7 \%$ ) in the last quarter demonstrating an increasing trend of regional technique for caesarean section. Majority of the epidural blocks were conducted by nurseanaesthetists while the subarachnoid blocks were administered by anaesthetists.

CONCLUSION: There is an overall low practice or usage of regional anaesthetic for caesarean section. A trend towards increasing administration of regional technique for caesarean section is demonstrated. A dedicated period for hand on the job workshop in regional blocks may enhance early and prompt acquisition of relevant skills in regional anaesthesia for caesarean delivery. WAJM 2009; 28(6): 380-383.
\end{abstract}

Keywords: Caesarean section, anaesthesia for, general anaesthesia, regional anaesthesia.

\section{RÉSUMÉ}

CONTEXTE: La plupart des articles ont déjà été effectués par césarienne sous anesthésie générale, mais il ya eu une tendance croissante à travers le monde dans l'utilisation de l'anesthésie régionale en tant que méthode privilégiée de l'anesthésie pour les accouchements par césarienne.

Objectif: évaluer l'évolution de la pratique de l'anesthésie régionale en cas de césarienne dans un hôpital tertiaire dans le sud-ouest du Nigeria.

MÉTHODES: Les dossiers chambre obstétriques d'exploitation à l'université Olabisi Onabanjo Teaching Hospital, Sagamu, le Nigeria ont été examinés pendant une période de vingt ans: Janvier 1986 à Décembre 2005. Les techniques d'anesthésie en cas de césarienne et le niveau de formation de l'anesthésiste assistant ont été notées.

RÉSULTATS: Un total de 1785 patients ont été livrés par césarienne au cours de la période de vingt ans. La plupart des patients [1578 $(88,4 \%)]$ ont une césarienne sous anesthésie générale, tandis que 207 (11,6\%) ont eu une anesthésie régionale. Sous-arachnoüdien bloc représenté $89(5 \%)$ des patients et 118 (6,6\%) ont eu la césarienne sous anesthésie péridurale. Cent dix (21,5\%) des techniques régionaux se trouvaient dans le premier trimestre de la période de 20 ans. Ce chiffre est tombé à huit (2\%) au deuxième trimestre, de zéro au troisième trimestre et a augmenté à $82(13,7 \%)$ au dernier trimestre montrant une tendance croissante de la technique régionale pour une césarienne. Majorité des blocs péridural ont été réalisées par des infirmiers anesthésistes tandis que les blocs sous-arachnoïdienne ont été administrés par les anesthésistes.

CONCLUSION: Il s'agit d'une pratique faible dans l'ensemble ou d'utilisation d'anesthésiques régionales pour une césarienne. Une tendance à l'augmentation de la technique de l'administration régionale en cas de césarienne est démontrée. Une période consacrée à la main sur l'atelier d'emplois dans les blocs régionaux mai améliorer l'acquisition précoce et rapide des compétences pertinentes dans l'anesthésie régionale pour la livraison césarienne. WAJM 2009; 28(6): 380-383.

Mots-clés: césarienne, l'anesthésie pour, l'anesthésie générale, l'anesthésie régionale.

Department of Obstetrics and Gynaecology, Olabisi Onabanjo University Teaching Hospital, Sagamu, Nigeria.

Correspondence: Lamina M. A. Department of Obstetrics And Gynaecology,

Olabisi Onabanjo University Teaching Hospital, P.M.B. 2001, Sagamu, Nigeria. E-mail: ademustapha_2003@yahoo.co.uk

Abbreviations: GA, General Anaesthesia; GB, Epidiural block; SAB, Subarachnoid block. 


\section{INTRODUCTION}

Most caesarean sections were previously performed under general anaesthesia but there has been an increasing trend worldwide to use regional anaesthesia as the preferred method of anaesthesia for caesarean delivery. ${ }^{1,2}$ The reason for the shift is not far-fetched and may not be unconnected with the hazards of general anaesthesia. The difficult failed intubation, regurgitation/aspiration pneumonitis, and hypoxaemia constitute major causes of anaesthetic maternal mortality. ${ }^{3-5}$ Conduction anaesthesia is currently regarded as a very safe method for a mother and for her newborn. This kind of anaesthesia reduces the risk of gastric contents aspiration and does not cause respiratory depression. ${ }^{2}$ The effects of anaesthetic drugs on the foetus ${ }^{2}$ and the desire of parents to be present (and conscious) at their child's delivery, ${ }^{6}$ however it occurs, may be enough reasons for the anaesthetist to have a rethink about the technique of anaesthesia for caesarean section.

Regional anaesthesia particularly subarachnoid block is more cost effective and a logical option for caesarean section in a third world environment. ${ }^{7}$ This should translate to greater utilization of regional anaesthesia for caesarean delivery especially in resource-poor countries where the cost of healthcare could be high and sometimes unaffordable. Earlier studies of the types and patterns of anaesthesia used for caesarean sections in tertiary obstetrics units in Nigeria ${ }^{8}$ showed that regional technique was infrequently employed for caesarean delivery. Nevertheless, there has been a steady rise in caesarean section rate in Nigeria ${ }^{9,10}$ and thus a consequent rise in the number of parturients requiring anaesthetic services. In spite of this rising rate of caesarean section, only one study in the mid-western part of Nigeria ${ }^{11}$ had shown a changing pattern of anaesthetic technique for caesarean section. Therefore, this study was undertaken to determine the trend of regional anaesthesia for caesarean section in a tertiary health institution in Nigeria.
SUBJECTS, MATERIALS，AND METHODS

The Olabisi Onabanjo University

Teaching Hospital, Sagamu is a relatively new teaching health centre established about 20 years ago and was accredited for postgraduate training in anaesthesia in Nigeria about five years ago. Nurse anaesthetists administered obstetric anaesthesia initially with gradual replacement with consultant anaesthetists and presently both consultant and trainee anaesthetists offer obstetric anaesthesia. The departmental regulation requires the presence of at least two anaesthetists and preferably one of them should be a senior resident or a consultant staff. The obstetric unit has a 24-hour coverage by anaesthetists. The hospital is a referral centre for the state and adjoining areas of other states.

\section{Data Collection}

The obstetric operating room records of the Olabisi Onabanjo University Teaching Hospital, Sagamu, Nigeria were reviewed for a period of 20 years (January 1986 to December 2005). All records of patients who had obstetric

\section{Table 1: Fequency of Techniques of Anaesthesia for Caesarean section I 1986-2005}

\begin{tabular}{lrrrr}
\hline Year & \multicolumn{5}{c}{ Frequency, Number (\%) } \\
\cline { 2 - 5 } & \multicolumn{1}{c}{ GA } & SAB & EB & Total \\
\hline 1986 & $70(57.9)$ & - & $5(42.1)$ & $121(6.8)$ \\
1987 & $72(59.5)$ & - & $49(40.5)$ & $121(6.8)$ \\
1988 & $169(100.0)$ & -- & -- & $169(9.5)$ \\
1989 & $35(100.0)$ & -- & -- & $35(2.0)$ \\
1990 & $56(84.8)$ & -- & $10(15.2)$ & $66(3.7)$ \\
1991 & $54(88.5)$ & -- & $7(11.5)$ & $61(3.4)$ \\
1992 & $74(100.0)$ & -- & -- & $74(4.1)$ \\
1993 & $29(96.7)$ & -- & $1(3.3)$ & $30(1.7)$ \\
1994 & $57(100.0)$ & -- & -- & $57(3.2)$ \\
1995 & $169(96.0)$ & $7(4.0)$ & -- & $176(9.9)$ \\
1996 & $53(100.0)$ & -- & -- & $53(2.9)$ \\
1997 & $55(100.0)$ & -- & -- & $55(3.0)$ \\
1998 & $57(100.0)$ & -- & -- & $57(3.2)$ \\
1999 & $52(100.0)$ & -- & -- & $52(2.9)$ \\
2000 & $58(100.0)$ & -- & -- & $58(3.2)$ \\
2001 & $70(100.0)$ & -- & -- & $70(3.9)$ \\
2002 & $129(95.6)$ & $6(4.4)$ & -- & $135(7.6)$ \\
2003 & $129(86.0)$ & $21(14.0)$ & -- & $150(8.4)$ \\
2004 & $108(81.2)$ & $25(18.8)$ & -- & $133(7.5)$ \\
2005 & $82(73.2)$ & $30(26.8)$ & - & $112(6.3)$ \\
\hline & $\mathbf{1 5 7 8 ( 8 8 . 4 )}$ & $\mathbf{8 9}(\mathbf{5 . 0})$ & $\mathbf{1 1 8}(\mathbf{6 . 6})$ & $\mathbf{1 7 8 5}(\mathbf{1 0 0 . 0})$ \\
\hline
\end{tabular}

GA, General anaesthesia; SAB,Subarachnoid anaesthesia; EB, Epidural block. anaesthesia during the study period were included in the stidy. The records were systematically analysed to determine the technique of anaesthesia administered. The records of those who had regional anaesthesia were subjected to further scrutiny. The type of regional anaesthesia employed was noted as well as the level of training of the anaesthetists or the most senior anaesthetist in the team.

\section{RESULTS}

A total of 1,785 parturients were delivered by caesarean section in the period under review (Table 1). Of these $1,578(88.4 \%)$ had caesarean section under general anaesthesia and 207(11.6\%) had regional anaesthesia. Subarachnoid block (SAB) accounted for $89(5 \%)$ while $118(6.6 \%)$ had epidural block (EB) as regional technique for the caesarean sections.

One hundred and ten (21.5\%) of the regional techniques as against $40(79.5 \%)$ were conducted in the first five years. This number for regional technique fell to eight $(2 \%)$ in the second five year period of 1991-1995 and to zero in the third five- 
year period, of 1996-2000 but rose to $82(13.7 \%)$ in the 2001-2005 period; indicating a change in the attitude in the technique of anaesthesia for caesarean section towards gradual adoption of regional technique.

Level of Training of the Anaesthetic Personnel: All the 118(57\%) epidural blocks were administered by experienced nurse anaesthetists of over five years and above in practice and consultant anaesthetists while the $89(43 \%)$ subarachnoid blocks were conducted by anaesthetists of at least two years in the department.

Table 2 shows the yearly trend of general and regional anaesthesia for caesarean section. There has been a gradual decline in the administration of general anaesthesia for caesarean section while there was a trend towards an increase in the administration of regional anaesthesia for caesarean section towards the end of the review period.

Table 2: Distribution of Caesarean sections by year and anaesthesia technque.

\begin{tabular}{ccc}
\hline Year & \multicolumn{2}{c}{ Number (\%) } \\
\cline { 2 - 3 } & $\begin{array}{c}\text { General } \\
\text { Anaesthesia }\end{array}$ & $\begin{array}{c}\text { Regional } \\
\text { Anaesthesia }\end{array}$ \\
\hline 1986 & $70(57.9)$ & $51(42.1)$ \\
1987 & $72(59.50)$ & $49(40.5)$ \\
1988 & $169(100.0)$ & - \\
1989 & $35(100.0)$ & - \\
1990 & $56(84.8)$ & $10(15.2)$ \\
1991 & $54(88.5)$ & $7(11.5)$ \\
1992 & $74(100.0)$ & - \\
1993 & $29(96.7)$ & $1(3.3)$ \\
1994 & $57(100.0)$ & - \\
1995 & $169(96.0)$ & $7(4.0)$ \\
1996 & $53(100.0)$ & - \\
1997 & $55(100.0)$ & - \\
1998 & $57(100.0)$ & - \\
1999 & $52(100.0)$ & - \\
2000 & $58(100.0)$ & - \\
2001 & $70(100.0)$ & $6(4.4)$ \\
2002 & $129(95.6)$ & $21(14.0)$ \\
2003 & $129(86.0)$ & $25(18.8)$ \\
2004 & $108(81.2)$ & $30(26.8)$ \\
2005 & $82(73.2)$ & \\
\hline & &
\end{tabular}

GA, General anaesthesia; RA, Regional anaesthesia.

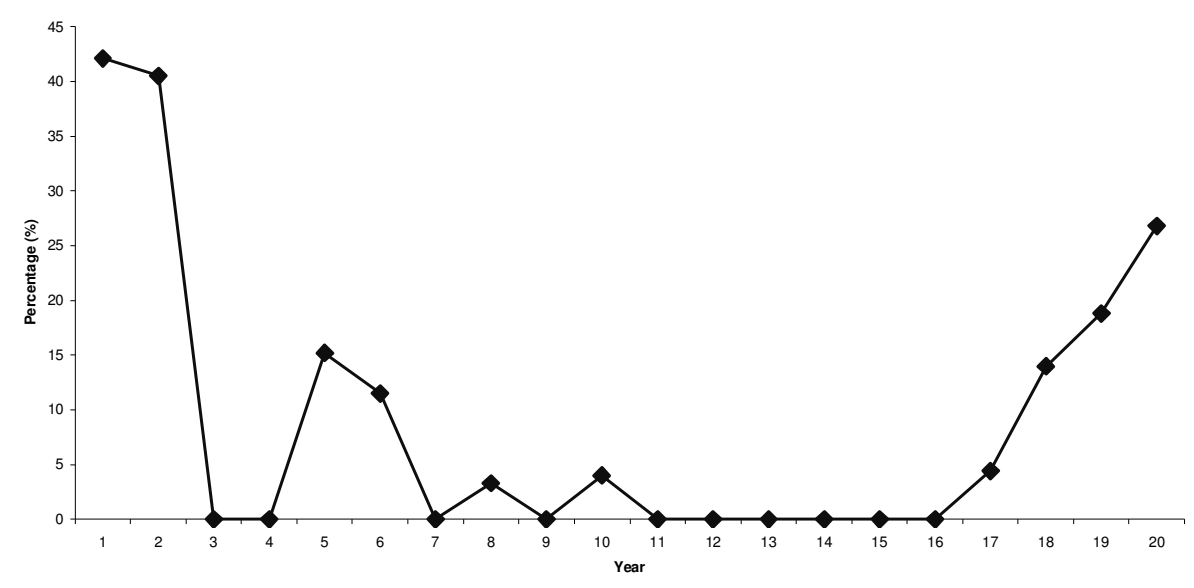

Figure: Yearly Trend of Regional Anaesthesia for Caesarean Section.

\section{DISCUSSION}

This study shows an overall low use of regional anaesthesia for caesarean section. The low use of regional technique $(11.6 \%)$ found in this study is similar to that reported by Aniata ${ }^{8}$ and Imarengiaye $^{11}$ in some Nigerian tertiary obstetric units. However, the long period covered by our survey makes it more representative of the likely prevalence of regional anaesthetic caesarean section in similar Nigerian tertiary health institutions. Aniata's study showed heterogeneity of anaesthetists as care giver as was the case in our hospital. It is pertinent to state that the scope of anaesthetic coverage may be affected by the availability of trained personnel.

Though there was a low use of regional anaesthetic caesarean section, there was a trend towards increasing use of regional technique for caesarean section in our study. This shift from general anaesthesia to regional for caesarean section is also a common event elsewhere. ${ }^{12,13}$ In a West Indian hospital, the proportion of general anaesthesia for caesarean section decreased from $85 \%$ in 1979 to $44 \%$ in $1989^{1}$ and may have decreased further. This worldwide trend is due to the perceived advantages of maternal safety and foetal well-being at birth. Regional anaesthesia has been suggested unequivocally as a safer and the preferred technique for caesarean section. ${ }^{2,14}$ Several reasons may be responsible for the low utilization of regional anaesthesia for caesarean section as seen by us. The depression of the national economy and the consequent depletion of the consultant staff may have led to failure to impact the relevant skills in regional techniques. Similarly, the various unfavourable fiscal policies and reduced budgetary allocation to health occasioned by the depressed economy, resulted in hospital's inability to provide consumable items like spinal needles. The net effect is the repeated administration of general anaesthesia and thus convenience with conduct of caesarean section under general anaesthesia.

In spite of the low use of regional anaesthetic caesarean section, epidural anaesthesia was favoured in the first eight years of the study and nurse anaesthetists who had qualified more than five years performed it. Subarachnoid block was the preferred regional technique in the last four years. Subarachnoid anaesthesia has several advantages over epidural anaesthesia. The ease of establishing subarachnoid block (SAB), the rapid onset of intense and reliable block without missed segments makes SAB more attractive for caesarean section. Subarachnoid anaesthesia also exposes the parturient and the foetus to smaller amounts of local anaesthetic agents. ${ }^{15}$ Epidural block demands high technical skill.

Certain anaesthetists in the period of study were more inclined to the use of regional anaesthesia for caesarean section. Individual interest or bias of the anaesthetists seemed to be a major factor in the choice of anaesthetic technique for caesarean section. The incidence of regional anaesthetic caesarean section 
was higher among the older anaesthetists. The departmental regulation, which requires the presence of a senior anaesthetist in the obstetric unit, may be contributory. With the trend of increasing administration of regional technique for caesarean section, the young trainee is likely to acquire the desired expertise much earlier than before. As soon as the junior resident is competent to attend to the obstetric patient, exposure to regional as well as general anaesthesia should be emphasized.

A properly conducted regional anaesthesia is the preferred option for caesarean delivery. Regional anaesthesia should be practiced more frequently for caesarean section when possible. More time in the training programme should be dedicated for regional blocks to enhance prompt acquisition of the relevant skills in regional anaesthesia. The obstetric patients will this way reap immensely the benefits of regional anaesthetic caesarean section.

\section{REFERENCES}

1. Crawford-Sykes A, Scarlett M,
Hambleton IR, Nelson M, Rattray C. Anaesthesia for operative deliveries at the University Hospital of the West Indies: a change of practice. West Indian Med J. 2005; 54: 187-91.

2. Bloom SL. Complications of anaesthesia for caesarean delivery. Obstet Gynecol. 2005; 106: 281-7.

3. Adeleye JA. Maternal mortality and caesarean section at the $\mathrm{UCH}$, Ibadan, Nigeria. Trop J Obstet Gynecol. 1988; 32: 61-6.

4. Tsen LC, Pitner R, Camann WR. General anaesthesia for caesarean section at a tertiary care hospital 19901995: indications and implications. Int J Obstet Anesth. 1998; 7: 145-6.

5. Lynch J, Scholz S. Anaesthetic-related complications of caesarean section. Zentralbl Gynakol. 2005; 127: 91-5.

6. Sindhvananda W, Leelanukrom R, Rodovant O, Sriprajtichai P. Maternal satisfaction to epidural and spinal anaesthesia for caesarean section. J Med Assoc Thai. 2004; 87: 628-35.

7. Okafor UV, Okezie O. Maternal and fetal outcome of anaesthesia for caesarean delivery in preeclampsia/ eclampsia in Enugu, Nigeria: a retrospective observational study. Int $J$ Obstet Anesth. 2005; 14: 108-13.
8. Aniata AO. Anaesthesia for caesarean section in some teretiary obstetric units in Nigeria-A pilot study. Nig Postgrad Med J. 1998; 5: 148-150.

9. Onifade A. Primary caesarean section in the multipara. J Nig Med Assoc. 1971; 1: 30-33.

10. Adeleye A, Okonofua F. Yearly trends in caesarean mortality in Ile-Ife. Trop $J$ Obstet Gynaecol. 1988; 1: 31-35.

11. Imarengiaye $\mathrm{CO}$, Ande $\mathrm{AB}$, Obiaya MO. Trends in regional anaesthesia for caesarean section at University of Benin Teaching Hospital. Nig J Clinial Practice. 2001; 4: 15-18.

12. Stamer UM, Wiese R, Stuber F, Wulf $\mathrm{H}$, Menser T. Change in anaesthetic practice for caesarean section in Germany. Acta Anaesthesiol Scand. 2005; 49: 170-6.

13. Jenkins JG, Khan MM. Anaesthesia for caesarean section: a survey in UK region from 1992 to 2002. Anaesthesia. 2003; 58: $1114-8$.

14. Kazimierak W. The mode of anaesthesia for caesarean section in the opinion of pregnant and delivering women. Ginekol Pol. 2005; 76: 49-53.

15. Cogarten W. Spinal anaesthesia for obstetrics. Best Pract Res Clin Anaesthesia. 2003; 17: 377-92. 